\title{
Mapping Accessibility Over Time
}

\author{
AHMED EL-GENEIDY and DAVID LEVINSON
}

University of Minnesota, 500 Pillsbury Drive S.E., Minneapolis, MN 55455, USA; geneidy@umn.edu

(Received 23 ${ }^{\text {rd }}$ July 2006; Accepted 26 ${ }^{\text {th }}$ October 2006)

\begin{abstract}
This study compares the changes in levels of accessibility over time in the Minneapolis - St. Paul region using two different modes (car and public transport). The importance of accessibility as a measure of land use and transportation planning performance in the region is revealed by comparing it over time. The longitudinal analysis being conducted shows increases in accessibility by car in most areas in the studied region, and a drop in accessibility by public transport over the period 1990 to 2000. The findings are compared to the levels of congestion in the region between the same time periods. This comparison shows the difference between the two measures and strengthens the importance of accessibility measures as a tool for monitoring and evaluating regional land use and transportation planning performance.
\end{abstract}




\section{Introduction}

The concept of "accessibility" has been coin in the transportation planning field for more than 40 years. Improving accessibility is a common element in the goals section in almost all transportation plans in the US (Handy, 2002). However, the term accessibility is often misused and confused with other terms such as mobility. Mobility measures the ability to move from one place to another (Handy, 1984; Hansen, 1959). The word accessibility is derived from the words "access" and "ability", thus meaning ability to access, where "access" is the act of approaching something. The word is derived from the Latin accedere "to come" or "to arrive." Here we concern ourselves with ease of reaching destinations or activities rather than ease of traveling along the network itself. One of the first definitions of accessibility in the planning field was suggested by Hansen (1959), who defines accessibility as a measure of potential opportunities for interaction.

High levels of mobility can, but do not necessarily reflect high levels of accessibility. High levels of accessibility can be present with low levels of mobility. The distinction between accessibility and mobility can be illustrated by comparing Manhattan and Manitoba. Travel in Manhattan is slow in terms of distance that can be covered in a given unit of time, yet one can reach many opportunities in that same short time because of the density of development. In contrast, road speeds in the largely rural Canadian province of Manitoba are quite high, but the accessibility is much lower because there are fewer opportunities to reach. Thus we say Manhattan has higher accessibility while Manitoba has higher mobility. Monitoring accessibility over time can be used as an indicator for the success of integrating land use and transportation planning in a region. In this paper we demonstrate the power of accessibility measures over time through visualizing these measures using various maps to better understand the changes in the land use and transportation system in the Twin Cities metropolitan region.

\section{Measures of Accessibility}

There are various ways to measure accessibility; the cumulative opportunity and the gravity-based measures are the most common. The isochronic or 
cumulative opportunity measure is one of the basic and early measures discussed in the literature (Vickerman, 1974; Wachs and Kumagai, 1973). This approach counts the number of potential opportunities that can be reached within a predetermined travel time (or distance). The cumulative opportunity is the simplest and easiest measure of accessibility either to calculate or to understand. The gravity-based measure (Hansen, 1959) is still the most widely used general method for measuring accessibility, although it is more complex in calculations and has some weaknesses. Both the cumulative opportunity and the gravity-based measures lead to almost the same answer when travel time is near to or less than 30 minutes (El-Geneidy and Levinson, 2006). Accordingly for simplicity in this paper we will use cumulative opportunity at 15 minutes of travel time as a measure of accessibility to demonstrate the power of an accessibility measure when mapped over time.

\section{Data and Methods}

When comparing accessibility measures over time it is important to unify the data sources and the measure of accessibility being used. For example if comparing accessibility to jobs in 1990 to accessibility to jobs in 2000, obtaining the number of jobs from the same data source is essential. Population and employment data used in this study were obtained from the U.S. Census Bureau at the transportation analysis zone (TAZ) level of analysis (U.S. Census Bureau, 2000). In this research we limit the analysis to two main transportation modes, car and public transport (which during this period in the Twin Cities was only a bus service, almost entirely on surface streets, with a few express routes on freeways). Similarly, if using a cumulative opportunity measure fixing the time range and methods for calculating travel time is a key. Comparing cumulative opportunity in 2000 to a gravity-based accessibility measure in 1990 is not possible since the methods are different. In this research we obtained travel time for both time periods from the transportation planning model that is maintained by the Twin Cities Metropolitan Council. This model estimates travel time between each TAZ and every other TAZ. Such analysis can be expanded to walking and bicycling if travel time were obtained for these modes and a smaller unit of analysis is used. 


\section{Importance}

The power of any accessibility measure is revealed when it is included in a longitudinal analysis. Comparison of accessibility measures over time can help public agencies to better understand how well the land use and transportation system is performing. For example if congestion levels increase in a city while levels of accessibility have increased as well, then this increase in accessibility can be used as an indicator for some kind of success in land use planning or market performance.

\section{General Comparative Study}

In this section a general comparison is conducted between levels of accessibility, using cumulative opportunity measures, in two time periods (1990 and 2000) using two modes of transportation (car and public transport). This comparison is conducted measuring accessibility to the number of jobs in each TAZ within 15 minutes of travel time. Travel time for car and public transport are obtained from the Metropolitan Council transportation planning model. For car, travel time is determined based on morning commute using shortest network path, and includes an intrazonal travel time to account for local travel and time to reach the transport network (walking to the car) from the origin or destination. Public transport travel time accounts for both in-vehicle and out-of-vehicle travel time, which includes time associated walking from TAZ centroids to the nearest bus stop, waiting time at the stop derived from the schedules, in-vehicle travel time obtained from schedules, and egress time from the nearest bus stop to the centroid of the destination TAZ. The public transport travel time calculations account for a maximum of two transfers and waiting time associated to them. It also accounts for the possibility of driving to park and ride locations between TAZs if service was not available near the centroids.

Figure 1 shows the level of cumulative opportunity measure of accessibility to the number of jobs that can be reached within 15 minutes of travel time from each TAZ during the morning peak in year 1990 using car, while Figure 2 shows a similar measure for the year 2000. Although nine categories are defined in the legend (the largest categories are unused in the graph, but would be relevant if we dealt with a time longer than 15 minutes, and wanted to compare that), observing changes in the level of accessibility over time in Figures 1 and 2 can be hard. 


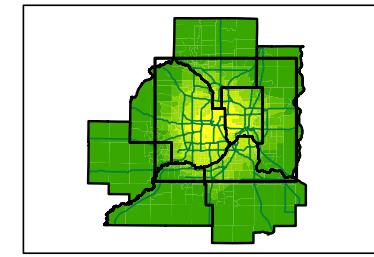

Number of Jobs Within 15 Minutes of Travel Time Mode: Car Year: 1990 Number of Jobs $0-50000$

$50001-100000$ 100001 - 200000 200001 - 400000 $400001-600000$ $600001-750000$ $750001-1000000$ 1000001 - 1250000 1250001 - 1550000

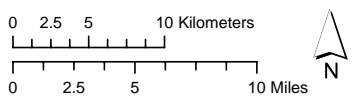
Data Sources Travel time : Met Council

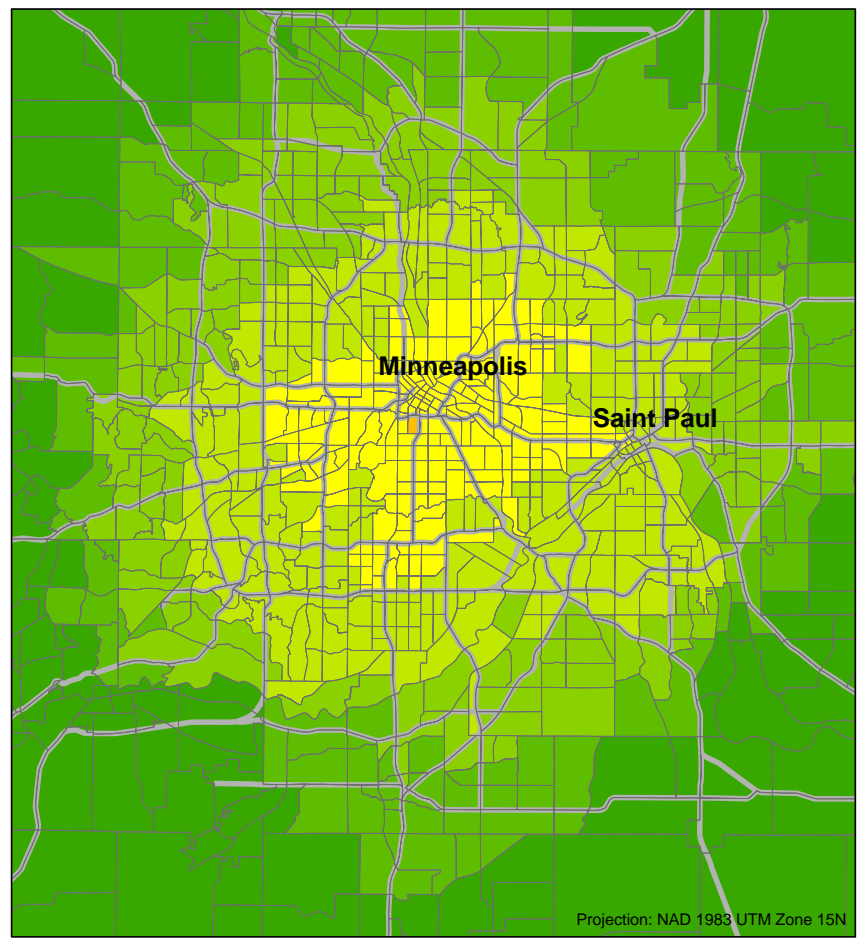

Figure 1 Number of jobs within 15 minutes of travel time in the year 1990 (Car).

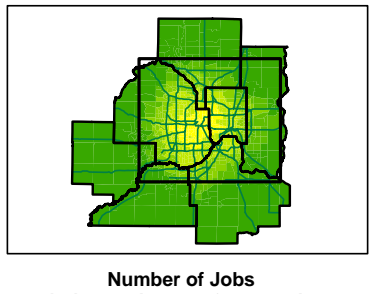

Number of Jobs
Within 15 Minutes of Travel Time Mode: Car
Year: 2000

\begin{tabular}{|c|}
\hline Number of Jobs \\
$0-50000$ \\
$50001-100000$ \\
$100001-200000$ \\
$200001-400000$ \\
$400001-600000$ \\
$600001-750000$ \\
$750001-1000000$ \\
$1000001-1250000$ \\
$1250001-1550000$ \\
\hline
\end{tabular}

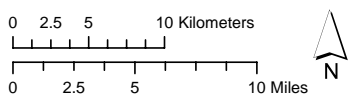
Data Sources Travel time : Met Council
GIS Files: US Census 2000

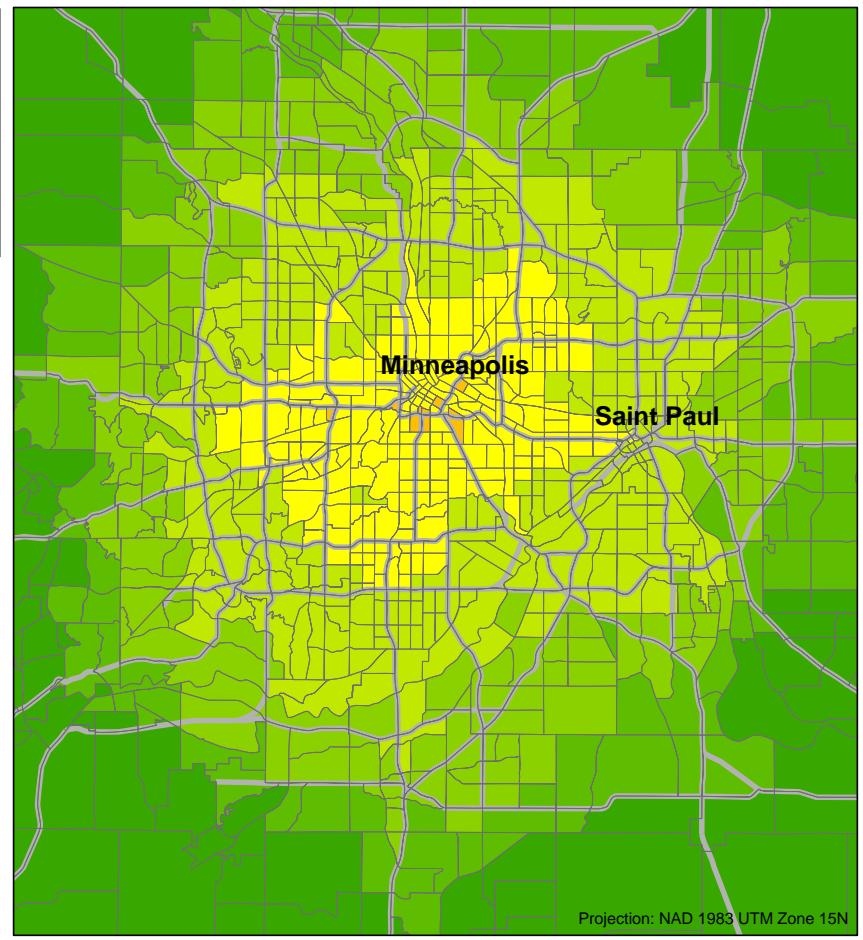

Figure 2 Number of jobs within 15 minutes of travel time in the year 2000 (Car). 
Figure 3 shows the difference between the number of jobs that can be reached within 15 minutes of travel time using car in the years 2000 and 1990. This figure helps in directly interpreting the change in the level of accessibility over time in the Twin Cities region. The change is calculated by subtracting the number of jobs in 1990 from the number of jobs in 2000 .
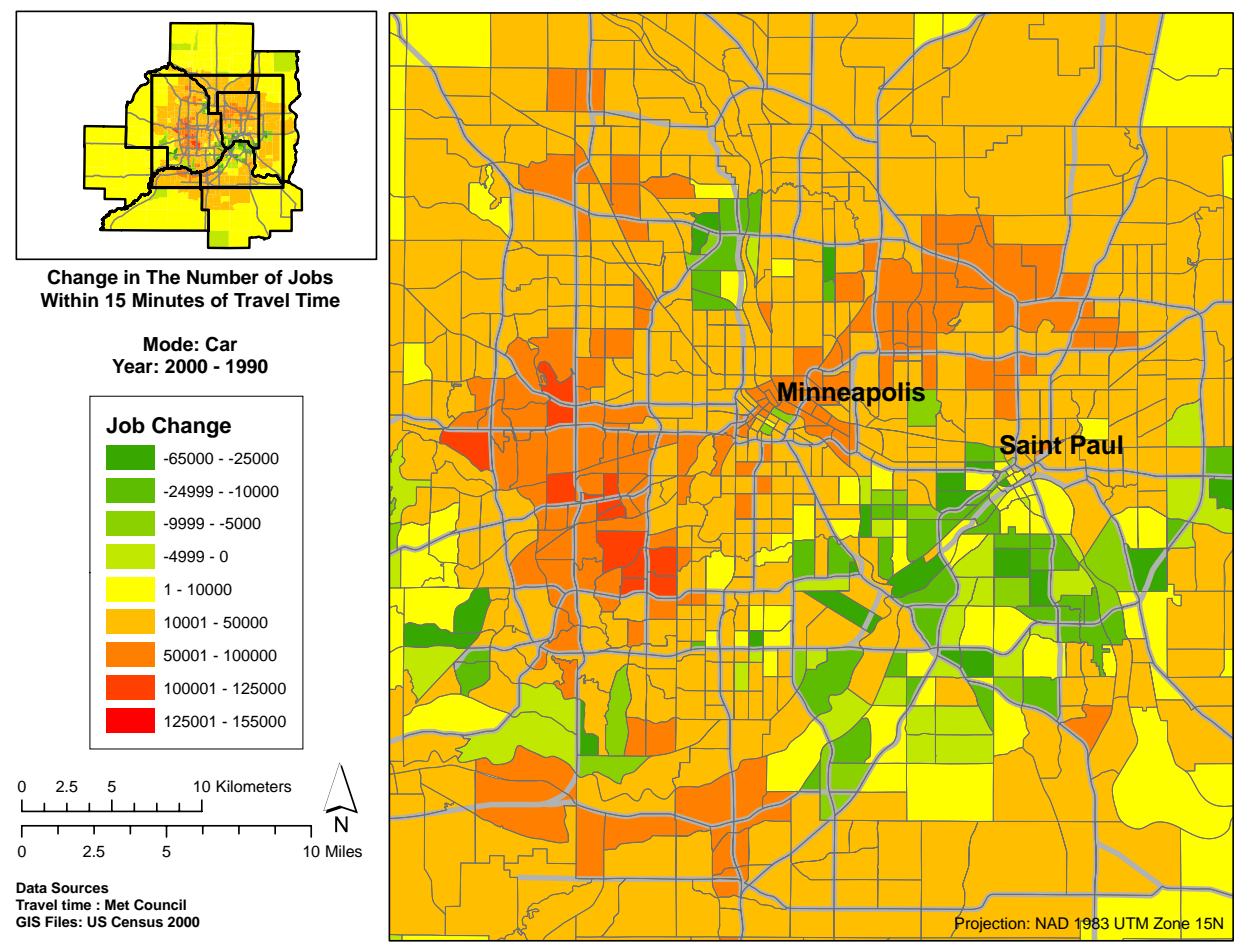

Figure 3 Change in the number of jobs within 15 minutes travel time (2000 - 1990) (Car).

Most of the region saw an increase in accessibility, while few areas, particular North Minneapolis and South Saint Paul, as well as areas along I-494 (the ring road) in the first and second ring suburbs saw a decline. This decline may be associated with increases in congestion rising faster than increases in job opportunities. The "rational locator hypothesis" (Levinson and Kumar, 1994) that both individual households and firms respond to changes in transportation supply by locating themselves to maintain or reduce commuting times may be an important explanatory factor in the general increase in accessibility. As congestion worsens, firms continue to suburbanize to be near their labor force, and retailers suburbanize to be 
near their customers, thereby increasing accessibility in suburban areas. Individual homeowners reorient themselves as well, choosing commutes that maximize their personal benefit, including travel time and home attributes.

Similarly, Figure 4 shows the difference between the number of jobs that can be reached within 15 minutes of travel time during the morning peak using public transport as the mode of transportation in the year 2000 and 1990.
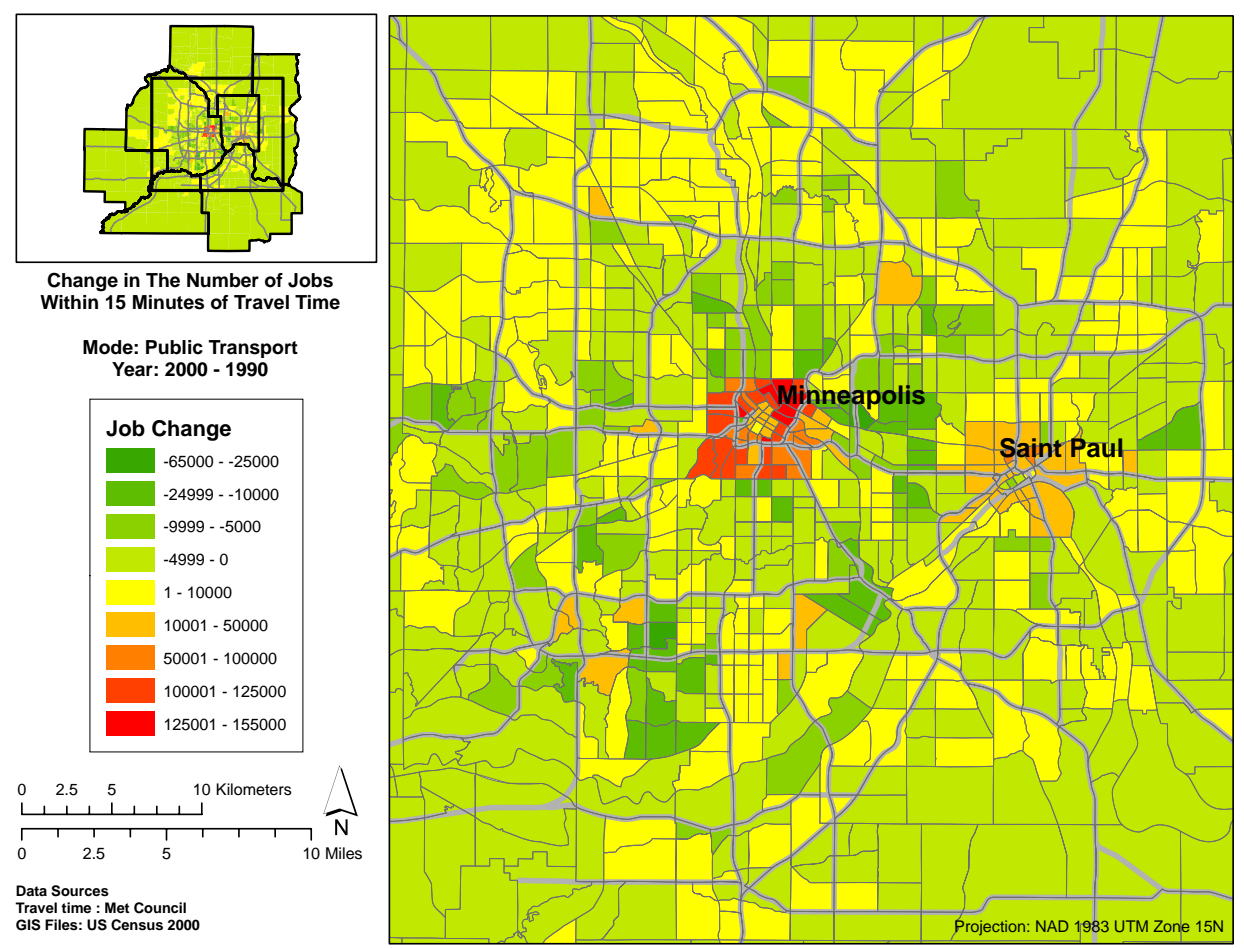

Figure 4 Change in the number of jobs within 15 minutes travel time $(2000$ - 1990) (Public transport).

It is clear from Figure 4 that changes in the number of jobs that can be reached within 15 minutes of travel time during the morning peak using public transport is small between the years 1990 and 2000 when compared to the change that was observed in Figure 3 for car. This is in part due to the lower accessibility available by public transport than by car. A decline was present in the level of accessibility in most areas. The only significant increases were found in the downtown areas. This reflects a Metro Transit policy to concentrate service in its strongest markets, downtown Minneapolis and St. Paul, and the University of Minnesota. There was an 
increase in the number of bus routes and frequency of service in this part of the region. Meanwhile downtown Saint Paul observed an increase in the level of accessibility to jobs at a lower rate compared to downtown Minneapolis, explained by its status as a smaller, and slower growing, center.

Figures 5 and 6 show similar results for number of people within 15 minutes travel time by car and public transport respectively. It is clear that areas that experienced increase in the levels of accessibility using car to jobs are those that experienced accessibility to residents. The increase in the levels of accessibility and the economic forces associated with it had an effect on some areas in the region leading to changes in the number of residents trying to be near these areas with an increase in job accessibility.
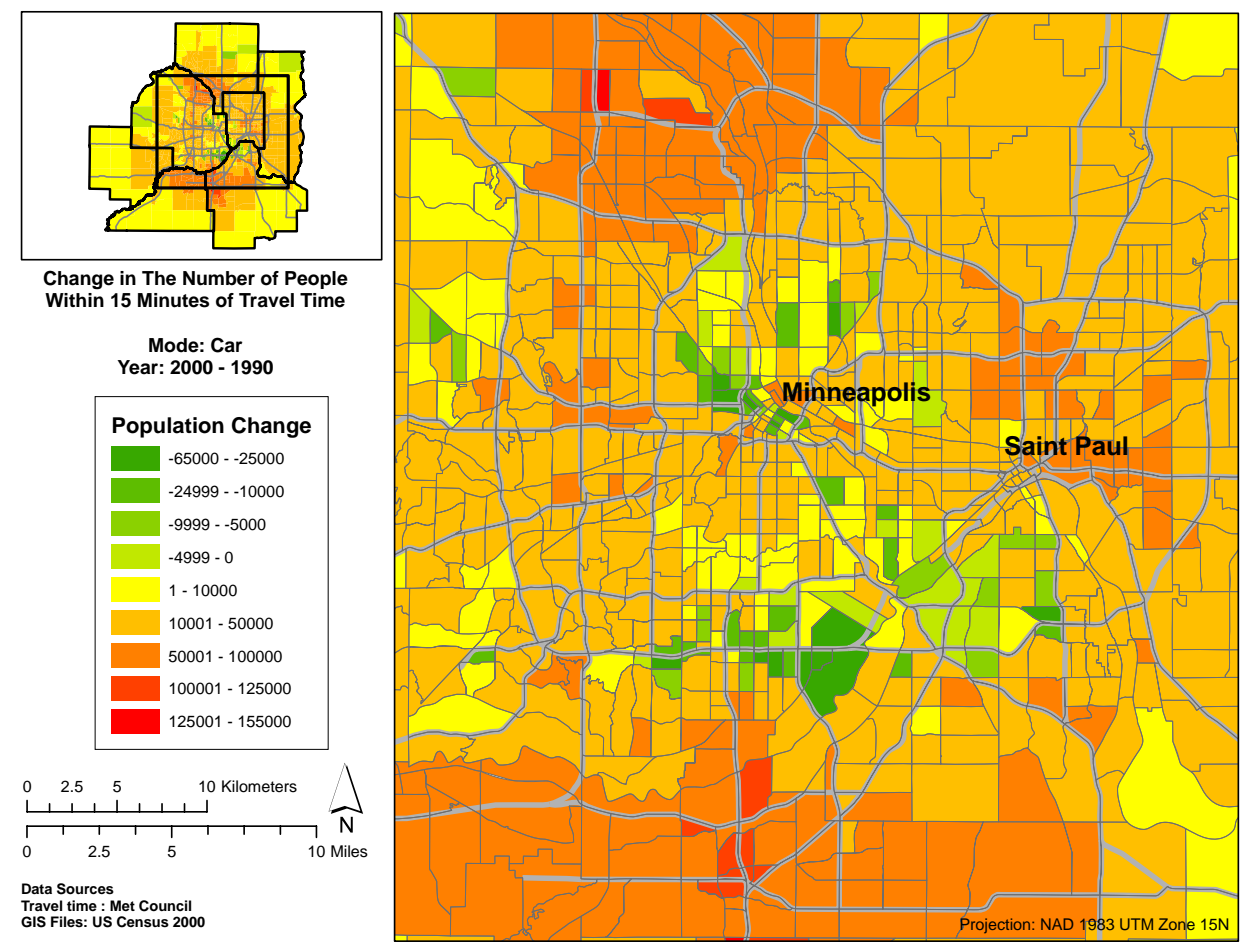

Figure 5 Change in the number of residents within 15 minutes travel time (2000 - 1990) (Car). 

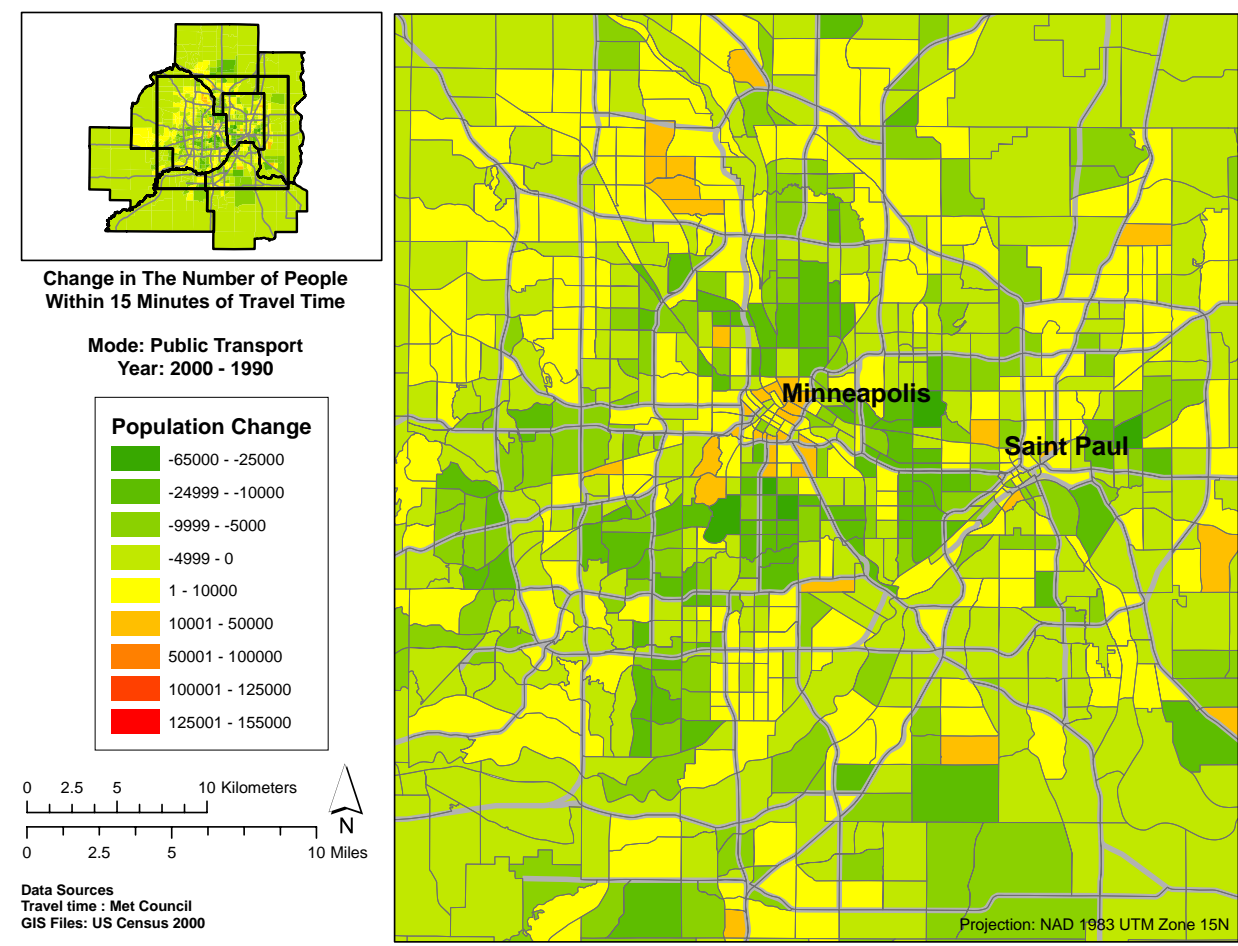

Figure 6 Change in the number of residents within 15 minutes travel time (2000 - 1990) (Public transport).

\section{Discussion}

This analysis provides a methodology for comparing accessibility over time. Monitoring the increase in the level of accessibility in the entire region it is clear that accessibility has increased in general in the region using car as a travel mode. Comparing these findings with levels of delays in the region between the years of 1990 and 2000 can help in better understanding the value of the accessibility measure. In 1990 the average annual delay per person during the peak period was 19 hours, while in 2000 the average annual delay per person during the peak period was 43 hours (Schrank and Lomax, 2005). This indicates an increase in the level of congestion that each traveler is exposed to during the morning peak in the Twin Cities region rose by more than the $100 \%$ during the period between 1990 and 2000 .

Using this morning congestion measure solely would lead us to conclude 
that there was a failure in how the transportation system is performing in the region. Yet the urban transportation system is too complex for one measure to evaluate its success or failure. Moreover, the transportation system cannot be separated from the land use and economic forces in the region, which drive development, yet governments and planning authorities, can have an effect on accessibility if they are viable economically.

Accordingly accessibility measures can be used as a better indicator for the performance of the land use and transportation system in a region, since it incorporates both travel times and changes in density, type, and location of activities (changes in opportunities).

In this study we used 15 minutes intervals of travel using both car and public transport for simplicity and to enable a comparison between the modes. Using 15 minutes of travel time interval for public transport is a small value for that mode. A typical public transport trip comprises walking time, waiting time, in vehicle time, and egress time. Some public transport trips have transfers too, which adds more time to the travel time. Furthermore, as most public transport in the Twin Cities involves buses on surface streets, it is also affected by changes in congestion.

\section{Conclusions}

The importance of accessibility as a measure of land use and transportation planning performance in the Twin Cities region was explored by comparing it over time. The longitudinal analysis showed improvements along the studied TAZs in terms of the level of accessibility to jobs and residents by car between 1990 and 2000. The increase in the levels of accessibility to jobs using car and the economic forces associated with it had an effect on some areas in the region leading to changes in the number of residents trying to be near these areas. This is clear from monitoring the accessibility to residents and where it has experienced positive changes. The findings were compared to the levels of congestion in the region between the same time periods. This comparison showed the difference between the two measures and strengthened the importance of accessibility measures as a tool for monitoring and evaluating land use and transportation planning performance in a region. While congestion increases suggest everything is getting worse, that is only looking at the costs of using the transportation system. The improvements in accessibility which combines costs (travel 
time) and benefits (opportunities), better explains why cities grow, and, for better or worse, why people prefer cars to public transport.

\section{Software}

All maps in this paper were generated using ArcGIS 9.2

\section{Acknowledgements}

This work was funded by the Minnesota Department of Transportation as part of the Access to Destinations project. The authors would like to thank Mark Filipi, Transportation Forecast/Analyst at the Metropolitan Council, for providing the travel time matrix and other data used in the study.

\section{References}

EL-GENEIDY, A. and LEVINSON, D. (2006) Access to destinations: Development of accessibility measures. Minnesota: Minnesota Department of Transportation.

HANDY, S. L. (1994) Highway blues: Nothing a little accessibility can't cure. Access, 5, 3-7.

HANDY, S. L. (2002) Accessibility -vs mobility- enhancing strategies for addressing automobile dependence in the us. Paper presented at the European Conference of Ministers of Transport, Tokyo, Japan.

HANSEN, W. (1959) How accessibility shapes land use. Journal of the American Institute of Planners, 25(2), 73-76.

LEVINSON, D. and KUMAR, A. (1994) The rational locator: Why travel times have remained stable. Journal of the American Planning Association, 60(3), 319-332.

SCHRANK, D. and LOMAX, T. (2005) The 2005 urban mobility report: 86 
Texas Transportation Institute.

U.S. CENSUS BUREAU (2000) American fact finder [online]. Available from http://factfinder.census.gov/home/saff/main.html [Accessed: December 13, 2006]

VICKERMAN, R. W. (1974) Accessibility, attraction and potential: A review of some concepts and their use in determining mobility. Environment and Planning A, 6, 675-691.

WACHS, M. and KUMAGAI, T. (1973) Physical accessibility as a social indicator. Socioeconomic Planning Science, 7, 327-456. 